\title{
O ÍNICIO DOS TESTES DE MÚLTIPLA ESCOLHA NO ACESSO À UNIVERSIDADE
}

WALTER SIDNEY PEREIRA LESER ${ }^{1}$

Atribuo o convite, para a minha presença nesta mesa redonda, ao desejo dos organizadores de terem aqui alguém que há mais de 60 anos ficou sabendo o que era um exame vestibular e, mais tarde, teve oportunidade de participação em tentativas de modificaçăo do antigo sistema.

Em 1928, eu estava, como examinado, concorrendo a uma das vagas na Faculdade de Medicina de São Paulo; o vestibular inclúa provas escritas e orais de física, química e história natural, com ponto sorteado, por vezes restrito a uma única questão. Era preciso obter, no mínimo, nota cinco em duas das provas escritas, para ser admitido as provas orais; com cinco, cinco e zero, satisfazia-se o requisito, mas com dez em uma e quatro vírgula nove nas outras duas, ocorria a eliminação. Talvez haja quem consiga encontrar justificativas para tal critério, mas eu confesso ser incapaz de fazê-lo. Nas provas orais, também com ponto sorteado, o único examinador de cada matéria dispunha de poucos minutos, medidos em ampulheta, para a arguição.

Fui aprovado, mas colegas meus do Ginásio do Estado, que eu sabia estarem mais bem-preparados, não tiveram a mesma sorte; fiquei convencido de que o sucesso ou o fracasso no exame dependiam largamente das causas de erro de avaliação que as condiçōes do exame propiciavam.

Essa convicção permaneceu na minha mente por muitos anos; em 1946, já como docente na Escola Paulista de Medicina, comecei, junto com Hélio

1 Professor de Estatistica na Escola Paulista de Medicina e professor de Higiene na Faculdade de Farmácia e Odontologia da USP. Secretário Estadual de Sáfde (1967-1970). Um dos idealizadores da Fundação Carlos Chagas (1964). 
Lourenço de Oliveira, a experimentar testes de múltipla escolha para avaliação de alunos da Cadeira de Higiene, com resultados que nos parecem satisfatorios.

Em 1952, fui incumbido de presidir uma das bancas examinadoras no vestibular da EPM; verifiquei que o sistema continuava o mesmo, persistindo a possibilidade de erros de julgamento e com características que deveriam favorecer os candidatos com mais capacidade de memorização de textos, o que não corresponde, necessariamente, a melhor nfvel intelectual.

A Congregação da Escola resolveu, então, para examinar essa hipótese, que em 1953 os candidatos fossem submetidos a um teste de nível mental, cujo resultado, sem que os interessados soubessem, não interferia no julgamento que continuaria baseado nas provas clássicas. Dos 75 aprovados, 17 , na opinião dos psicológos que realizaram o teste, alcançaram escores insuficientes para permitir previsão de rendimento satisfatório no curso médico. $O$ acompanhamento desses estudantes, 58 suficientes e 17 insuficientes, durante o curso, evidenciou, em duas formas de análise dos resultados, diferença significante $(\mathrm{p}<1 \%)$ no rendimento escolar, favorecendo o grupo suficiente (Revista Brasileira de Estudos Pedag6gicos, vol. 37, 1962).

Reconhecendo a validade das críticas feitas ao sistema de exame vestibular, a Congreção da Escola aprovou a substituição, já no vestibular de 1954, das provas escritas por testes de múltipla escolha, acrescentando-se um teste de nível mental e um de redação, organizado pelo Professor Octávio Martins, do Instituto Nacional de Estudos e Pesquisas Educacionais (INEP). Por sugestão do Prof. Martins, os candidatos também escreveram uma dissertação sobre tema dado: no INEP, foi feita avaliação desses textos, por técnica semi-objetiva, trabalhando, independentemente, dois professores especializados. A correlação entre as notas conferidas por eles foi menor do que a calculada entre a média delas e a nota dada pelo teste, comprovando que este, sem incorrer em erros devidos à subjetividade, forneceu resultados que traduziam adequadamente os fornecidos pela dissertação.

Em 1955, o Prof. Alípio Corrêa Neto, então Reitor da USP, convocou a Assembléia Universitária, indicando-me como relator do tema: Modificação no Sistema dos Exames de Admissão às Escolas Superiores. No relatório apresentado (Revista da Associação Médica Brasileira, setembro, 1956), após ampla discussão dos vários aspectos da questão, figuraram as seguintes sugestões:

a) inclusão de teste de nível mental;

b) substituição das provas escritas e orais por testes de múltipla escolha, tendo em conta a superioridade que estes apresentam no que se refere à validade e precisão dos resultados, bem como a possibilidade de aperfeiçoamento progressivo mediante a analise por itens;

c) conveniência da criação de um órgão central, reunindo equipamentos, materiais e técnicos especializados para elaboraçãoe análise dos testes, recursos de que as Faculdades, isoladamente, não poderiam dispor. 
Acrescentou-se, ainda, a possibilidade de exame conjunto, abrangendo várias Faculdades, evitando o desgaste físico, emocional e econômico a que se sujeitam os candidatos que concorrem a diferentes vestibulares.

O Relatório alcançou pequena repercussão, não ocorrendo modificação no sistema vestibular então vigente, com exceção das que já haviam sido adotadas na EPM. S6́ em 1963 foi resolvida a criação do CESCEM (Centro de Selęão de Candidatos ds Escolas Médicas), cujo âmbito logo se estendeu a outras Faculdades com currículo biologico (veterinária, farmácia, e bioquímica e biologia). Foi institurda depois a Fundação Carlos Chagas, que organizou o exame em 1965. A colaboração do Centro de Cálculo Numérico assegurou a utilização de computadores para a apuração e análise, o que se tornou indispensável pelo aumento do número de Faculdades participantes, deste e de muitos outros Estados. A Fundação Ford forneceu uma doação substancial, para compra de equipamentos para leitura ótica e impressão de provas, e para um bom número de bolsas destinadas à formação de técnicos no exterior.

Deve ser lembrado que, considerando o fato de que, colocado como marco divisório entre o curso secundário e superior, o exame vestibular projeta sua influência năo só sobre o futuro, pela qualidade do material humano que irá fornecer às Faculdades, mas também sobre o passado pela modificação que imprime à conceituação dos objetivos do ensino do grau médio. Na realidade, das muitas mazelas que afligem o ensino secundário, algumas são atriburdas ao efeito coercitivo que a programação dos vestibulares exerce sobre os estudantes. De uma forma geral, o objetivo básico do ensino secundário - o de conferir ao aluno uma formação humanística capaz de permitir-lhe a visão das ciências, das artes, das letras e da filosofia, compativel com a fase da evolução de seu espírito, pode ser totalmente deturpado. Em seu lugar instala-se uma especialização precoce, mesquinha nos seus propósitos e feroz no seu imediatismo.

Assim, já em 1965, a Fundação Carlos Chagas incluiu, no exame, além do teste de nível intelectual, testes de física, química, biologia, redação, matemática, inglês e conhecimentos gerais, este último abrangendo, especialmente, história, geografia, literatura e informações sobre o mundo moderno. Mais tarde, foi oferecida, como alternativa para o teste de inglês, o de outra língua estrangeira.

Obrigações outras que assumi impediram que continuasse a ter participação nas atividades da Fundação Carlos Chagas, a partir de 1967. Quase 25 anos haviam decorrido, desde que começara a me interessar pelo problema da seleção de candidatos: ao longo deles havia formado conviç̧ões firmes a respeito do que deveria ser feito. Embora ciente de que o modelo adotado em 1965 era passível, como se previra, de aperfeiçoamento ditados pela experiência e pelas pesquisas recomendadas, mormente as referentes ao acompanhamento do rendimento escolar, parecia-me possível admitir que haviam sido conseguidos avanços consideráveis, eliminando-se as principais causas de erro apontadas no passado. Desde então, alteraçōes foram sendo introduzidas; 
pretendo examinar as mais importantes e mostrar porque não posso considerálas aceitáveis.

1. A eliminação do teste de nivel mental, a despeito de todas as evidências coligidas, tanto no pais como no exterior, apontando seu significado como criterio preditivo do desempenho de alunos de cursos superiores. $E$ bem conhecido dos professores o obstáculo que representa, para o aprendizado de toda uma classe, a presenfa de alguns elementos menos bem dotados intelectualmente.

2. Substituiçäo do teste de redação por uma dissertação, com esquecimento da farta documentação comprobatoria, do grau de imprecisão inevitável no julgamento de provas desta natureza.

3. Substituição de testes de múltipla escolha por provas discursivas, implicando erros ligados à subjetividade da correção e, dado o reduzido número de questöes, excluindo a possibilidade de cobertura de toda a materia. Isso me faz lembrar do tempo do ponto sorteado.

Ao que me parece, uma das justificativas para os procedimentos apontados nos itens 2 e 3 repousou na aceitação da hipótese de que as deficiências no trato do vernáculo e na capacidade de expressão do pensamento, por parte de alunos de cursos superiores, surgiram somente apos a utilização de testes nos vestibulares, resultando da influência que as "cruzinhas" teriam exercido no ensino secundário. Nunca houve, que eu saiba, dados coligidos que, de alguma forma, comprovassem a veracidade dessa hipotese, nem tenho conhecimento de que tenha sido apurada, até agora, modificação, para melhor, nos aspectos referidos, que pudesse ser atribuída à vigência das provas discursivas. Outra justificativa apresentada dizia respeito ao risco decorrente de acertos casuais nas provas em que, como se dizia, as respostas eram dadas por "cruzinhas". É fácil demonstrar que, com as oito provas que constituíam o exame, com cerca de 600 questões envolvendo cinco alternativas, a influência dos acertos casuais se tornava muito reduzida, ou praticamente nula.

4. Finalmente, e principalmente, a introdução, com caráter eliminatorio, de um teste de "cruzinhas". Curiosamente, não tenho tido conhecimento de criticas a tal teste, por parte daqueles que clamavam contra o risco de acertos casuais.

Do resultado desse teste depende a possibilidade do candidato passar para a segunda fase. Vejamos o que pode acontecer: o escore obtido é a soma dos acertos nas questōes que o candidato era capaz de responder corretamente, ou seja, envolvendo matéria que ele sabia, e dos que aconteceram, por acaso, nas questōes cuja resposta ele arriscou.

Como o teste, neste ano, teve o número de questões reduzidas para 72 (sem ser considerada a correspondente redução da validade), calculei uma tabela baseada na distribuição binomial de probabilidades, em que figuram as percentagens de candidatos que alcançariam cada um dos diferentes escores, a partir do número de questões que realmente sabiam responder. 
TABELAA - 1

TABELA 1 - PERCENTAGEM DE CANDIDATOS QUE ALCANÇARAM O ESCORES ABAIXO INDICADOS PELA SOMA DE ACEKTOS EM QUESTÓES QUE ERAM CAPAZES DE RESPONDER ACERTADAMENTE E DE ACERTOS CASUAIS EM QUESTÖES CUJA RESPOSTA ARRISCARAM, EM TESTE COM 72 QUESTÓES E 5ALTERNATIVAS.

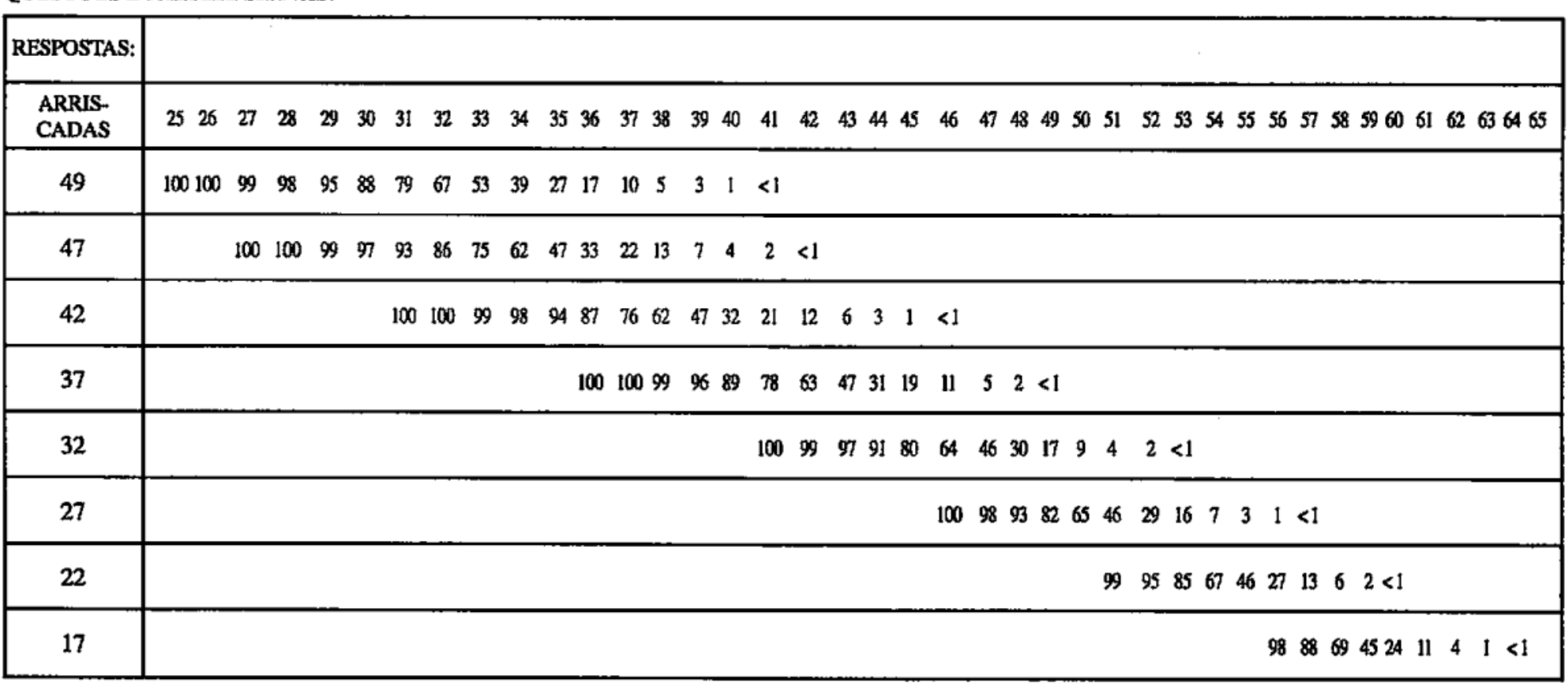


Vemos, por exemplo, que, dos candidatos que "sabiam" respostas a 30 questões e arriscavam as outras 42 respostas, $32 \%$ poderiam conseguir o escore 40; o escore 41 poderia ser alcançado por $21 \%$, e assim por diante. Suponhamos que o escore de corte para a segunda fase seja 40; então, dos candidatos que "sabiam" igualmente 30 das questões, $32 \%$ passariam para a segunda fase e $68 \%$ seriam eliminados, meramente em função de acertos casuais. Ainda mais, podemos ver que dos candidatos que "sabiam" 35 respostas, $89 \%$ passariam, mas $11 \%$ seriam eliminados, ainda que "soubessem" mais do que o grupo anterior que só "sabia" 30. Pior ainda, dos candidatos que sర́ sabiam 25 questões, $4 \%$, com mais sorte, também passariam. Ou seja, aceitam-se ou eliminam-se candidatos com igual preparo; eliminam-se candidatos mais preparados do que outros aceitos. Não acredito que se possa apresentar justificativa racional para tais clamorosos erros.

Além disso, novamente focalizando o exemplo anterior, pode-se admitir que aqueles candidatos à segunda fase, com 40 pontos, consigam, nesta, ingressar em uma Faculdade; os demais, com igual preparo, perderam esta possibilidade de sucesso.

Como se vê, neste teste eliminatório, os acertos casuais assumem importância por vezes decisiva, mas, ao que me consta, não mais constituem motivo de preocupação. A justificativa do teste eliminatório como forma de reduzir o número de candidatos, permitindo a realização de provas discursivas, deixa, a meu ver, de ter significado, tendo em conta as irrespondíveis críticas que são contra elas formuladas. Nunca foi necessário eliminar candidatos nos exames da Fundação Carlos Chagas; com testes de escolha múltipla, a apuração e a análise são facilmente realizadas por computadores.

5. Em 1955 foi proposta a criação de um orgão central, para realização dos vestibulares; em 1964, ele foi criado. Depois, as Universidades se sentiram diminuídas por não assumirem essa responsabilidade e passaram a ter, de volta, exames separados. Dois pontos exigem consideraçöes: em primeiro lugar, é preciso saber se todas dispõem de pessoal qualificado para a tarefa, o que é indispensável. Nunca vi, publicado, o resultado de analise de provas; $\boldsymbol{e}$ possivel que tenha sido feita. A publicação permitiria avaliar-se, pela variação, ano apbs ano, dos coeficientes de discriminação e de fidedignidade, por exemplo, se houve melhoria da qualidade dos exames. Em segundo lugar, é preciso lembrar que, como no passado remoto, os candidatos em busca de uma vaga são obrigados a participar de sucessivos exames, com desgaste ftsico, emocional e econômico.

Para encerrar, quero me colocar na posição dos candidatos, procurando expressar o que suponho que eles esperam do vestibular:

- ter assegurada plena possibilidade de demonstrar sua qualificação, frente aos vários critérios adotados para classificação; 
- certeza de julgamento com o maior grau de precisäo que se possa alcançar.

Não acredito que, com a forma atualmente adotada para a seleção, por algumas instituições, seja lícito admitir que essas esperanças sejam atendidas. Estou convencido de que já estivemos mais próximos de fazê-lo; lamentavelmente, em muitos pontos, regredimos para posições inaceitáveis vigentes no passado. 
